\title{
Mogan Gölü'ndeki bazı balık türlerinde vitellogenin proteininin elektroforetik karşılaştırılması
}

\section{Electrophoretic comparison of vitellogenin protein in some fish species in Mogan Lake}

\author{
Göktuğ Gül1* • Aysel Çağlan Karasu Benli² - Figen Erkoç3 \\ ${ }^{1}$ Gazi Üniversitesi Sağlık Hizmetleri Meslek Yüksekokulu, 06830 Gölbaşı-Ankara, Turkey \\ ${ }^{2}$ Gazi Üniversitesi Fen Bilimleri Enstitüsü, 06500 Teknikokullar-Ankara, Turkey \\ ${ }^{3}$ Gazi Üniversitesi Gazi Eğitim Fakültesi Biyoloji Eğitimi Anabilim Dalı, 06500 Teknikokullar - Ankara, Turkey \\ *Corresponding author: goktuggul@gazi.edu.tr
}

Gül, G., Karasu-Benli, A.Ç. \& Erkoç, F. (2016). Electrophoretic comparison of vitellogenin protein in some fish species in Mogan lake (in Turkish with English abstract). Ege Journal of Fisheries and Aquatic Sciences, 33(2): 151-156. doi: 10.12714/egejfas.2016.33.2.09

\begin{abstract}
Öz: Bu çalışma, balıkçılık ve rekreasyon alanı olarak kullanılan Mogan Gölü'nde (Ankara - Türkiye) Ocak-Mayıs 2013 ayları arasında yürütülmüştür. Gölde yaşayan balık türlerinden Cyprinus carpio, Carassius gibelio, Tinca tinca ve Esox lucius türlerinin erkek ve dişi bireylerinin kan plazmasında elektroforetik SDS-Page (Sodyum Dodesil Sülfat Poliakrilamid Jel Elektroforezi) metodu ile vitellogenin (VTG) proteini araştııımış ve türler arası karşılaştırma yapılmışıı. Bu metot için Biometra marka dikey elektroforez cihazı kullanılmışır. Üreme döneminde C. carpio, T. tinca ve E. Lucius'un erkek bireylerinde vitellogenin proteini saptanmıştır. Göl ortamındaki çeşitli kirleticilerin bu sonuçlar üzerinde etkili olduğu düşünülmektedir. Bu çalışmada elde edilen bulgulara göre kullanılan testin iyi bir biyo-belirteç olduğu anlaşılmıştır.
\end{abstract}

Anahtar kelimeler: Vitellogenin, elektroforez, Cyprinus carpio, Carassius gibelio, Tinca tinca, Esox lucius

\begin{abstract}
This study was carried out between January and May 2013 in Mogan Lake (Ankara - Turkey) which is used as fisheries and recreation area. The Vitellogenin (VTG) protein was investigated by the electrophoretic SDS-Page (Sodium Dodecyl Sulfate Polyacrylamide Gel Electrophoresis) method from the blood plasma of female and male members of Cyprinus carpio, Carassius gibelio, Tinca tinca and Esox lucius species living in the lake and VTG proteins have been compared. In this method, Biometra brand vertical electrophoresis device has been used. During the breeding period, VTG proteins have been determined among male members of $\mathrm{C}$. carpio, T. tinca, and $\mathrm{E}$. lucius. It is taught that our results might be affected by various contaminants found in the lake. According to results of our investigation, it was understood that this method is one of the effective bio-indicators.
\end{abstract}

Keywords: Vitellogenins, electroforesis, Cyprinus carpio, Carassius gibelio, Tinca tinca, Esox lucius

\section{GíRiş}

Günümüzde teknolojik gelişime paralel olarak genetik alanında da önemli ilerlemeler görülmektedir. Kullanılan birçok kimyasal maddenin ya da bileşiklerinin sebebiyet verdiği yapısal kromozom anomalilerinin tespiti de genetik biliminin ilerlemesi ile mümkün hale gelmiştir (Schiffmann ve De Boni, 1991; Fenech, 2000).

Vitellogenin deneyi ovipar omurgalı hayvanlarda östrojen tespitinde en sık kullanılan in vivo biyo-deneylerden biridir (Sumpter ve Jobling, 1995; Tyler vd., 1996). VTG proteini 17ßestradiol (E2)'ye cevap olarak karaciğerde üretilir ve karaciğer hepatositleri içerisinde muhafaza edilerek gelişmekte olan oositlere taşınır (Lazier ve McKay, 1993; Van den Belt vd., 2003). Bütün ovipar omurgalılar gibi teleost balıklarda da VTG'nin ovaryumlara alınması reseptör-aracılı endositoz ile gerçekleşir. VTG reseptörleri oosit membranında yerleşiktir. Bağlanma yerinin çekim gücü yüksektir ve yaklaşık $100 \mathrm{kDa}$ büyüklüğündedir. Vitellogenezin başlaması ile plazma VTG düzeyleri hızla yükselir ve gelişim evresi boyunca yüksek kalır (Allner vd., 1999; Tyler ve Sumpter, 1996). VTG gelişmekte olan oositin intiyacı olan aminoasitler, enerji, lipit ve kalsiyumun tamamını olmasa da büyük kısmını karşılar. VTG'nin üretimi östrojene bağımlıdır, dolayısı ile dişilerle sınırıdır. VTG erkek balıkların plazmasında normalde çok düşük düzeyde bulunmaktadır (Allner vd., 1999; Tyler ve Sumpter, 1996). Erkek balıklarda VTG geni bulunur, ancak sentezlenebilmesi için hem doğal hem de sentetik östrojenlere maruz kalarak tetiklenmesi gerekir (Tyler vd., 1996). Endokrin bozucu kirleticilerin (EDC) birçoğu östrojen uyarıcı etki yaparlar. Ayrıca birçok çalışmada EDC'lerin doğal steroid $17 \beta$-östrojeni taklit 
ettiği bildirilmiştir. Söz konusu kirleticilerin östrojenik aktivitesi zayıftır (Donohoe ve Curtis, 1996; Coldham vd., 1997; Van den Belt vd., 2003; Çek ve Sarıhan, 2010).

Sucul ortamda birden çok maddenin kirletici olarak bulunması sinerjistik etki göstererek toksisitelerinin artmasına neden olmaktadır. Diğer taraftan söz konusu bileşiklerin (ftalatlar, PCB'ler, poliklorin-bifeniller, vb.) lipofilik özelliğinden dolayı sucul canlılarda 100000 katına kadar biyoakümülasyon gösterebilmektedir (Çek ve Sarıhan, 2010).

Endokrin sistemde bozucu etki yaratan kimyasal maddeler, balıkların biyokimyasal sistemlerini agonistik veya antagonistik olarak etkilerler (Colborn vd., 1993). Balıklar sucul besin zincirinin en üst kademesinde bulunduğundan ekosistem etkilerinin değerlendirilmesinde indikatör olarak tercih edilmektedir. Son yıllarda yapılan araştırmalara göre insan yapımı kimyasallardan kullanımda olan 100000'den fazla östrojenik aktiviteli madde bilinmektedir (Tyler vd., 1996; Bjorkblom vd., 2011; Çek ve Sarıhan, 2010). Organoklorin pestisitleri, alkil fenol kimyasalları ve ftalatları kapsayan birçok ürün ksenoöstrojen olarak tanımlanmıştır (Jobling ve Sumpter, 1993; Jobling vd., 1996; Routledge vd., 1998; Van den Belt vd., 2001; Van den Belt vd., 2003). Birçok çevresel östrojen sanayi kaynaklıdır. Bunlara ek olarak farmasötik östrojenlerden 17aethinylestradiol (EE2) ve doğal östrojenlerden E2, estron, estriol atıksu arıtma çalışmalarının bir ürünü olarak ortaya çıkmaktadır (Shore vd., 1993; Stumpf vd., 1996; Ternes vd., 1999; Van den Belt vd., 2003).

Mogan Gölü, Ankara için önemli sucul rekreasyon alanı olması ile birlikte floristik ve faunistik açıdan zengin bir yapıya sahiptir. Göl son yıllarda çevresel tehditlerin etkisiyle ötrofik özelliktedir (Karul vd., 2000). Çevresindeki kirlilik unsurlarının göle taşınımı söz konusudur. Tarımsal atık bazıı kimyasalların yağmur ve drenaj suları ile taşınımı ve sivrisinek mücadelesi gibi uygulamalar sonucu doğrudan ya da dolaylı olarak bulaşma ile gölün kirlilik yükü artmaktadır (Fakıoğlu ve Polatsü, 2005). Göldeki bazı balık türleri avlanmakta ve tüketilmektedir.

Su kaynaklarında EDC'ler ve doğal östrojenler iz miktarda bulunmaktadırlar. Sucul ekosistemlerin indikatör canlısı olan balıkların kanında VTG gibi östrojen bağımlı proteinlerin ekotoksikolojik risk değerlendirmesinde önemli olduğu belirtilmektedir (Allner vd., 1999). Bu nedenle Mogan Gölü'nde yaşayan balıklardan $C$. carpio, $C$. gibelio, $T$. tinca ve $E$. lucius bireylerinde üreme dönemlerine denk gelen aylarda ekotoksikolojik etkilerin VTG analizi ile tespiti amaçlanmıştır. Deneyin hassasiyeti ve güvenilebilirliği VTG'ye karşı üretilmiş antikorun özelliklerine bağımlı olduğundan, plazmada elektroforetik yöntemle VTG varlığının gösterilmesi ekotoksikolojik yönden tercih edilmektedir (Tyler ve Sumpter, 1990; Asturiano vd., 2005).

\section{MATERYAL VE YÖNTEM}

Bu çalışma, Ankara'nın güneyinde yer alan ve önemli rekreasyon alanı oluşturan Mogan Gölü'nde gerçekleştirilmiştir.
Mogan Gölü, Ankara'nın güneyinde yer alan ötrof sığ bir tatlısu gölüdür. Örnekler gölde belirlenen 4 istasyondan temin edilmiştir (Şekil 1). Belirlenen istasyonlara ait koordinatlar aşağıda verilmiştir.

1. İstasyon K $39^{\circ} 47^{\prime} 38^{\prime \prime} \mathrm{D} 32^{\circ} 47^{\prime} 58^{\prime \prime}$

2. İstasyon $\mathrm{K} 39^{\circ} 47^{\prime} 8^{\prime \prime} \mathrm{D} 32^{\circ} 48^{\prime} 11^{\prime \prime}$

3. İstasyon $\mathrm{K} 39^{\circ} 45^{\prime} 7^{\prime \prime} \mathrm{D} 32^{\circ} 46^{\prime} 47^{\prime \prime}$

4. İstasyon $\mathrm{K} 39^{\circ} 46^{\prime} 10^{\prime \prime} \mathrm{D} 32^{\circ} 47^{\prime} 5^{\prime \prime}$

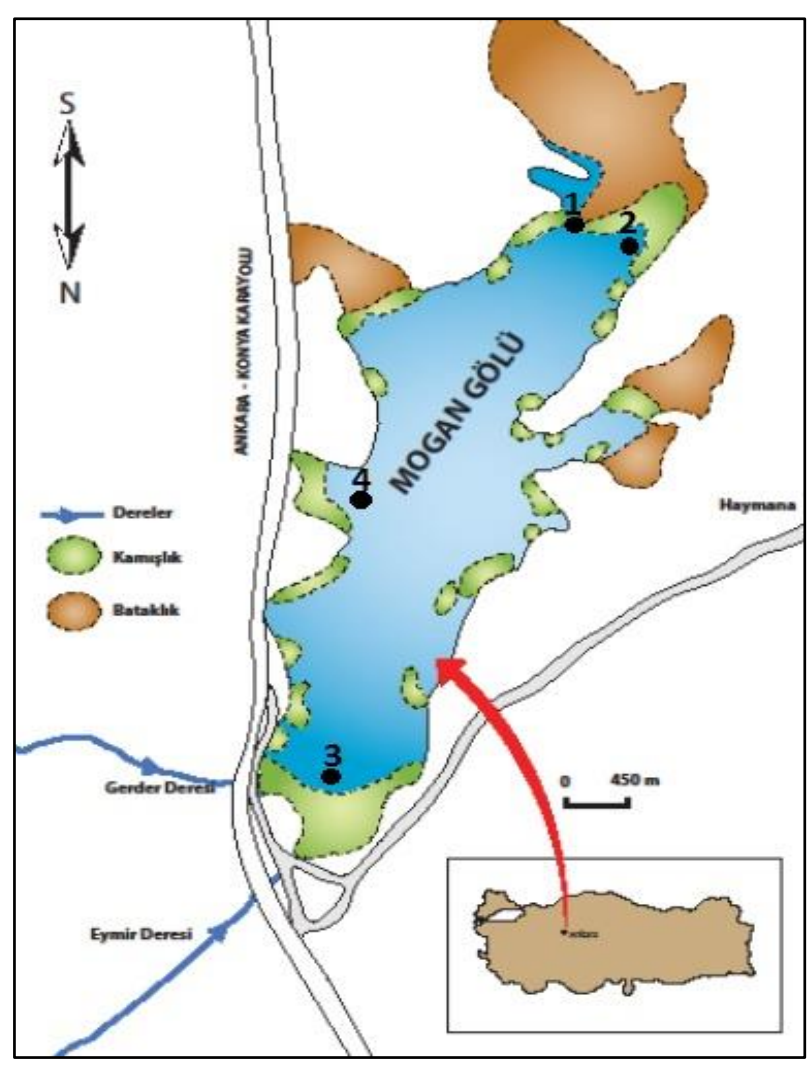

Şekil 1. Mogan Gölü örnekleme lokalizasyonları

Figure 1. Mogan Lake sampling localizations

Göldeki balık türlerinin üreme dönemlerini içeren OcakMayıs 2013 ayları arasında örnekler alınmıştır. Balık örneklerinin avlanmasında 18x18; 30x30; 40x40; 50x50; 60x60 ve $70 \times 70 \mathrm{~mm}$ göz açıklıklarına sahip fanyalı ağlar kullanılmıştır. Balık örnekleri canlı olarak laboratuvara getirilmiş, total boyları (mm) ölçülmüş ve ağırlıkları $\pm 1 \mathrm{~g}$ hassasiyetli terazi ile tartılmıştır. Örneklerin yaş tayinleri pullardan yapılmıştır (Lagler, 1956).

Her örnekten vitellogenin proteini analizi için kaudal venadan 5 ml'lik enjektör ile kan alınmıştır. Kanın pıhtılaşmasını engellemek için iç yüzeyi Nevparin marka heparin ile tamamen heparinize edilmiş enjektörler kullanılmıştır. Balıkların kan örneklemesi sırasında Quinaldin (25 mg/L) ile anestezi uygulanarak acı hissi yok edilmiştir (Keleştemur ve Özdemir, 2010). Kan örnekleri Hettich marka soğutmalı eppendorf santrifüjde plazması ayrılarak vitellogenin analizi için hazır hale getirilmiştir. Protein yapısının 
bozulmaması için $\quad-80^{\circ} \mathrm{C}$ ' de muhafaza edilmiştir. Deneyde plazma içerisindeki her bir proteinin, molekül ağırlıklarına göre, jel üzerinde tek bant oluşturabilmesine imkân veren Sodyum Dodesil Sülfat Poliakrilamid Jel Elektroforezi (SDS-Page) metodu ve bu metot için Biometra marka dikey elektroforez cihazı kullanılmıştır. Bu metotta proteinler Sodyum dodesil sülfat (SDS) varlığında hazırlanan polimerize olmuş jel üzerinde yürütülmektedirler (Allner vd., 1999; Asturiano vd., 2005). Ayırıcı jel hacmen $\% 10$ konsantrasyon ile yükleme jeli ise hacmen $\% 5$ konsantrasyon ile hazırlanmıştır. Deney sırasında optimum manyetik yürütmenin sağlanabilmesi için konsantre yürütme tamponu $1 / 5$ oranında distile su ile seyreltilmiştir. Hazırlanan her jel de 1. kuyuya Marker (Page Ruler) koyulmuştur. Diğer jeller için her yükleme kuyusuna farklı örneğe ait kan plazması olmak üzere $3 \mu$ l protein ile $7 \mu \mathrm{l}$ boya karıştırılarak yüklenmiştir. Son olarak elektrik akımı 70 Amper ve 140 Volt olacak şekilde proteinlerin jel içerisinde yürütülmesi işlemi başlatılmıştır. Yürütme işlemi jelin alt ucundan $1 \mathrm{~cm}$. yükseklikteyken sonlandırılmıştır.

\section{BULGULAR}

Avlanan balıklardan Cyprinus carpio (L., 1758), Carassius gibelio (Bloch, 1782), Tinca tinca (L., 1758) ve Esox lucius (L., 1758) bireylerinin yaş, total boy ve ağırlıkları saptanmıştır. Bazı C. carpio ve $T$. tinca bireylerinde gonad gelişimi olmadığı için cinsiyet tayini yapılamamıştır. C. gibelio bireylerinin tamamının dişi olduğu belirlenmiştir. Yaş, boy ve ağırlık verileri Tablo 1' de verilmiştir.
Tablo 1. Balık türlerinin yaş, boy ve ağırlık dağılımı

Table 1. Age, length and weight distributions of fish species

\begin{tabular}{|c|c|c|c|c|}
\hline Tür & $N$ & $\begin{array}{c}\text { Yaş } \\
\text { Dağılımı }\end{array}$ & $\begin{array}{c}\text { Ortalama Boy } \\
\text { Dağılımı (cm) } \\
\text { (Min-Max) }\end{array}$ & $\begin{array}{c}\text { Ortalama } \\
\text { Ağırlık Dağılımı } \\
\text { (g) } \\
\text { (Min-Max) }\end{array}$ \\
\hline C. carpio & 5 & III-IV & $\begin{array}{c}32.31 \\
(26.00-36.30)\end{array}$ & $\begin{array}{c}410.40 \\
(241.73-559.80)\end{array}$ \\
\hline C. gibelio & 6 & $\|-|| \mid$ & $\begin{array}{c}28.28 \\
(26.00-30.00)\end{array}$ & $\begin{array}{c}366.94 \\
(303.45-430.92)\end{array}$ \\
\hline T. tinca & 5 & III-IV & $\begin{array}{c}26.86 \\
(24.50-28.00)\end{array}$ & $\begin{array}{c}273.30 \\
(201.75-347.71)\end{array}$ \\
\hline E. lucius & 12 & IV-VI & $\begin{array}{c}44.03 \\
(37.00-52.00)\end{array}$ & $\begin{array}{c}544.56 \\
(395.36-970.00)\end{array}$ \\
\hline
\end{tabular}

$\mathrm{Bu}$ araştırmada SDS-Page deneyinde elde edilen jel görüntüleri incelenmiş, C. gibelio dışında kalan diğer tüm erkek bireylerin en az birinde VTG tespit edilmiştir. Vitellogenin analizi için elektroforez yöntemi ile yürütülen deney sonucunda daha önce VTG'si indüklenmiş örnekler ile avlanan balıklara ait örnekler karşılaştırılmıştır (Şekil 2, Şekil 3). C. carpio, T. tinca ve $E$. lucius bireylerinin vitellogeninlerinin yalnız dişilerde değil erkeklerde de görüldüğü tespit edilmiştir. Araştırmada $C$. carpio, C. gibelio, T. tinca ve E. lucius' un tüm ergin dişi bireylerinde VTG saptanmıştır. Incelen türlerden C. gibelio dışındaki diğer türlerin en az bir erkek bireyinde VTG proteini görülmüştür. Analizde cinsel olgunluğa erişmemiş ve üreme periyodu dışında kalan balıkların plazmalarında vitellogenin proteinine rastlanmamıştır.

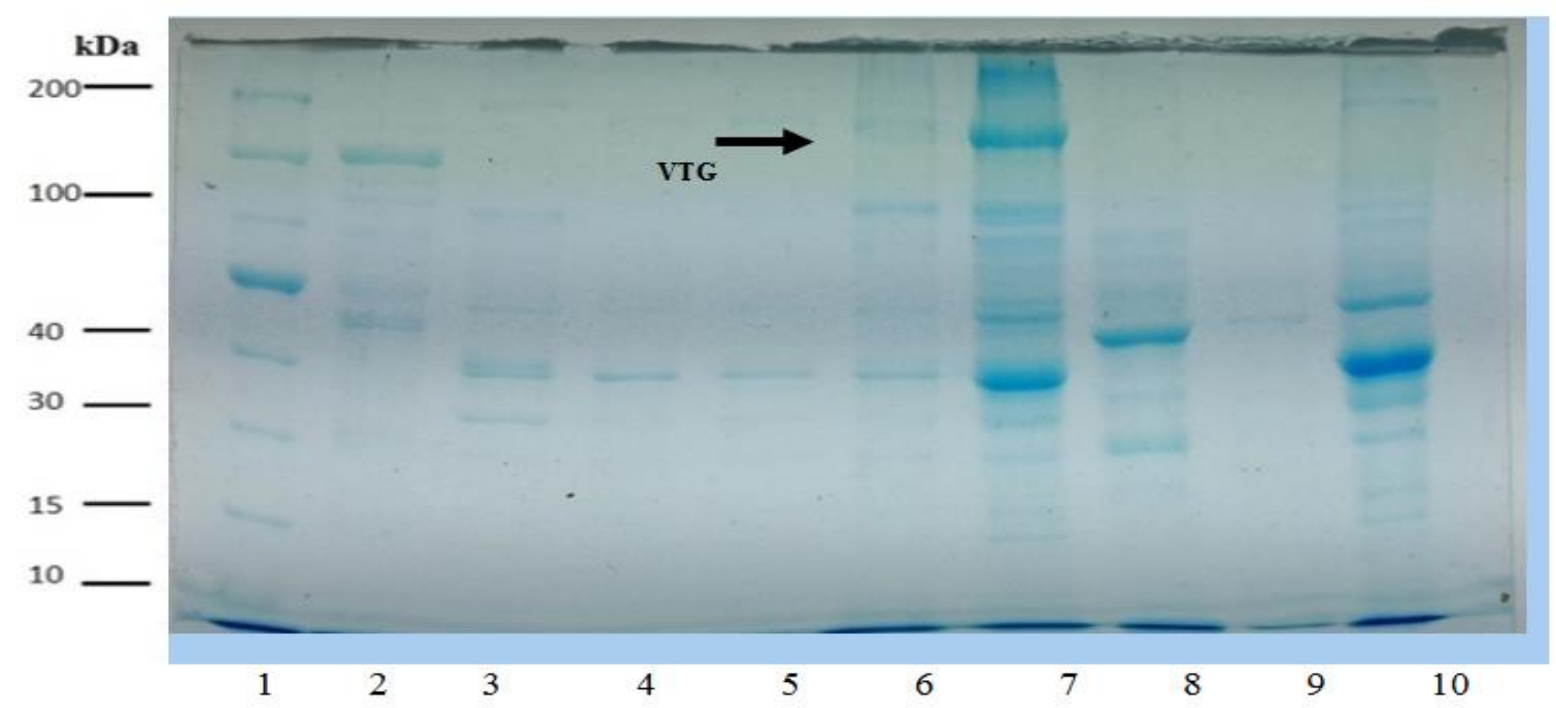

Şekil 2. VTG tespiti yapılan jel görüntüsü-1: 1. Marker, 2. 9 C. carpio $(25 \mu \mathrm{g} / \mathrm{L}$ östradiol-beta'ya maruz bırakılmış jüvenil sazan plazması), 3. $9 E$.

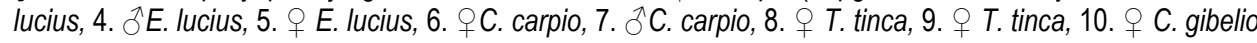

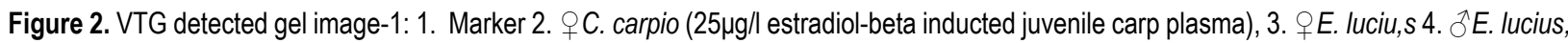

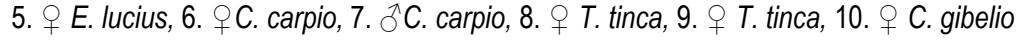




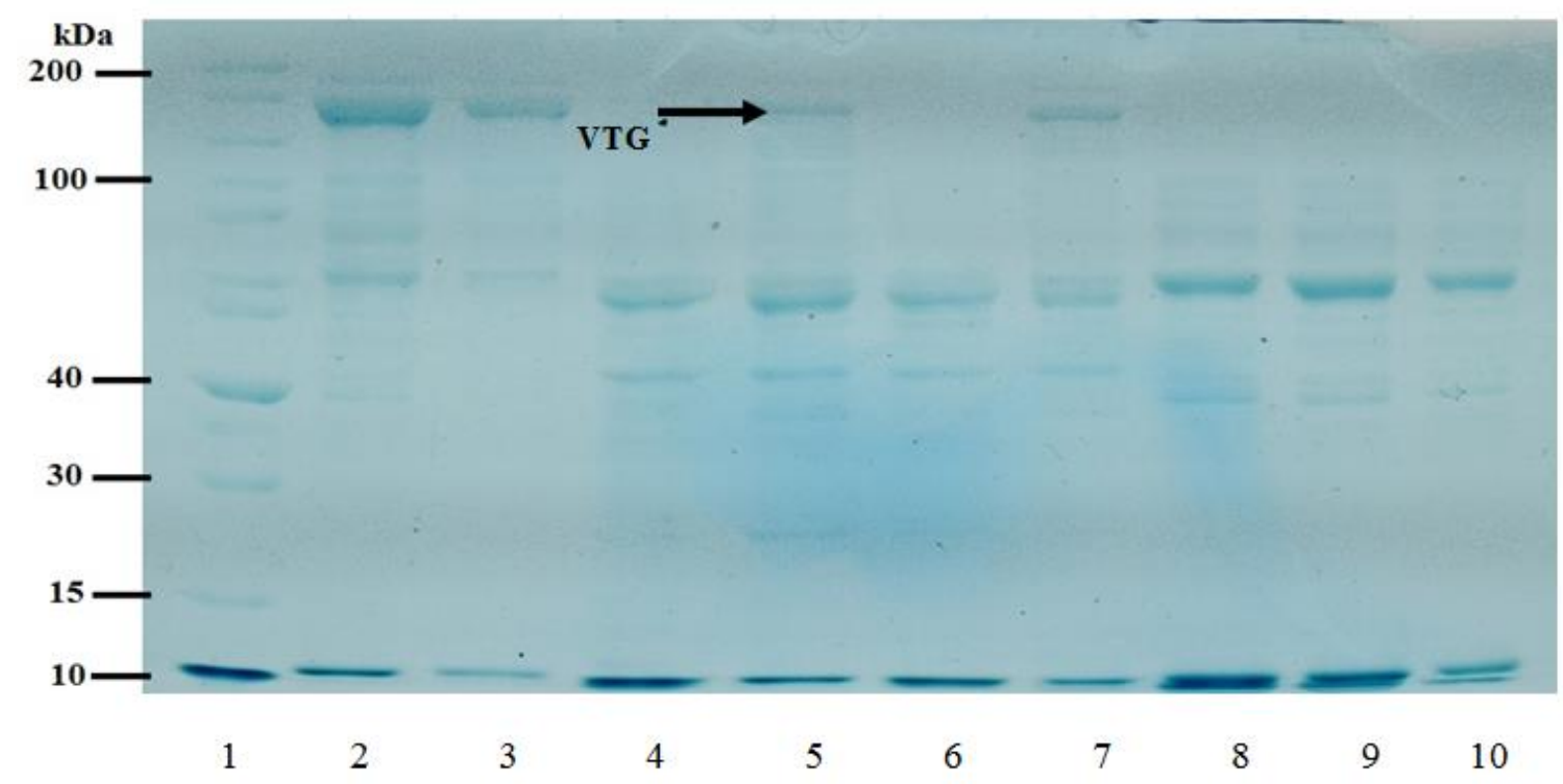

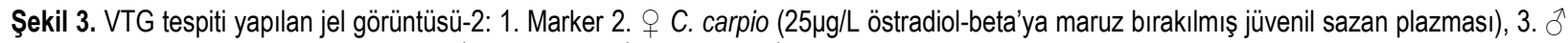

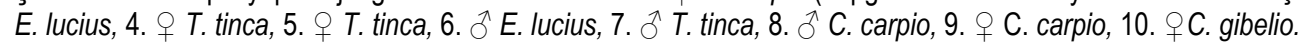

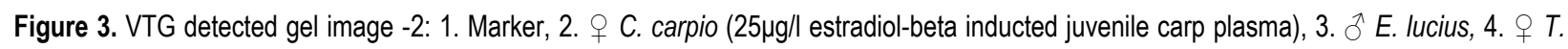

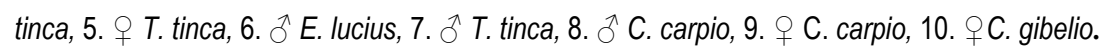

\section{TARTIŞMA VE SONUÇ}

Mogan Gölü'nde yaşayan C. carpio, C. gibelio, T. tinca ve E. lucius bireylerinin kan plazmalarında elektroforetik vitellogenin analizi yapılmıştır. Deneyin hassasiyeti ve güvenilebilirliği VTG'ye karşı üretilmiş antikorun özelliklerine bağımlı olduğundan, plazmada elektroforetik yöntemle VTG varlığının gösterilmesi ekotoksikolojik yönden tercih edilmektedir (Tyler ve Sumpter, 1990; Asturiano vd. 2005).

Bu araştırmadaki bulgulara benzer olarak Tyler vd. (1996), Cyprinidae familyasından Leuciscus leuciscus ve Tinca tinca' ların VTG'lerinin RIA testinde çapraz reaksiyon verdiğini bildirmiştir. Cyprinidae dışındaki diğer 8 familyada (Clupeidae, Salmonidae, Siluridae, Cyprinodontidae, Gasterosteidae, Cichlidae ve Cottidae) ise vitellogenik balıklardan alınan plazmada radyoimmün (RIA) testinde çok düşük oranda çapraz reaksiyon rapor edilmiştir. Sonuç olarak Cyprinidae familyasından olmayan balıkların VTG'sinin, Cyprinidae'lerin VTG' sinden immünolojik olarak önemli derecede farklı olduğu bildirilmiştir. Aynı çalışmada dişi balıkların plazma VTG düzeyleri üreme döngüsü boyunca ölçülmüş ve vitellojenik ovaryum gelişiminin zirve yaptığı dönemde en yüksek seviyede olduğu belirtilmiştir. Meucci ve Arukwe (2005) Salmo salar'ın jüvenil bireylerinde BPA (bisfenol A)'ya maruz kalmadaki VTG ve zona radiata proteinlerini elektroforez ve ELIZA testi ile araştırmış, BPA'nın iyi bir ekotoksikolojik biomarker olarak geliştirilebileceğini belirtmişlerdir. Maltais ve Roy (2009) Kanada'dan Moxostoma hubbsi ve Moxostoma macrolepidotum türlerinin östradiol ile indüklenen jüvenil bireylerinde hem plazma hem de mukusta vitellogenin tespit etmişlerdir. Çalışmalarında elektroforez, ELIZA yöntemiyle 150 kDa molekül ağırlığında bir büyük ve 120 kDa'da da küçük bir bant bulmuşlardır. Böylece yüzey mukusunun vücut dışında bulunan bir vitellogenin örneği olarak geliştirilebileceğini öne sürmüşlerdir. Ayrıca türün üreme biyolojisinin araştırılmasında da kullanılabileceğini belirtmişlerdir. Brion vd. (2000) Oncorhynchus mykiss, Gobio gobio ve Leuciscus cephalus; Asturiano vd. (2005) Liza aurata; Hennies vd. (2003) Cyprinus carpio ve Perca fluviatilis; Roubal vd. (1997) Pleuronectes vetulus; Ndiaye vd. (2006) Oreochromis niloticus; Allner vd. (1999) Leuciscus idus ve Danio rerio (östrojen indüksiyonundan sonra); Nagler vd. (1987) Salmo gairdneri (östrojen indüksiyonundan sonra); Yamaguchi vd. (2009) Oryzias latipes; Yamanaka vd. (1998) Fundulus heteroclitus türlerinde yaptıkları çalışmalarda VTG proteini izole ederek elektroforetik araştırmalar yapmışlardır. Bu çalışmalarda erkek ve juvenil bireylerde VTG proteini tespiti ile Mogan Gölü'ndeki erkek balıklarda VTG proteininin tespit edilmesi arasında benzerlik olduğu anlaşılmıştır.

VTG proteini, çevresel kirleticilerin EDC aktiviteli olarak üreme siklusunda antropojenik etki yaparak VTG sentezine sebep olabilecekleri anlaşılmaktadır. Çevresel kirleticilerin balık türlerinde özellikle erkek bireylerin üreme döngüsünde aksamalara ve bozulmalara sebep olabileceği düşünülmektedir. Bu durumun da Mogan Gölü'nde yaşayan 
balıkların endokrin sistemini etkileyen antropojenik kirlilik kaynaklarına yani EDC aktiviteli bileşiklere maruz kaldığını düşündürmektedir. Bu çalışmada kullanılan biyolojik yöntemin, kirlilik tespiti yönünde iyi bir biyo-belirteç olarak kullanılabileceği belirlenmiştir.

Su sistemlerinde sadece su kalite parametreleri üzerinden kirlilik ve etkilerinin belirlenmesi beklenen sonuçların alınmasında yeterli veriler olmayacaktır. Bu nedenle sucul ekosistem bileşenlerinin önemli grubunu oluşturan ve besin kaynağı konumunda önem taşıyan balıklardaki genotoksik araştırmaların periyodik olarak yapılması gerekmektedir.

\section{KAYNAKÇA}

Allner, B., Wegener, G., Knacker, T. \& Stahlschmidt-Allner, P. (1999) Electrophoretic determination of estrogen-induced protein in fish exposed to synthetic and naturally occurring chemicals. The Science of the Total Environment, 233(1-3): 21-31. doi:10.1016/S0048-9697(99)00176-X

Asturiano, J.F., Romaguera, F., Aragon, P., Atienza, J., Puchades, R. \& Maquieira, A. (2005). Sandwich immunoassay for determination of vitellogenin in golden grey mullet (Liza aurata) serum as a field exposure biomarker. Analytical and Bioanalytical Chemistry, 381: 1152-1160. doi:10.1007/s00216-004-3049-4

Bjorkblom, C., Mustamaki, N., Olsson, P., Katsiadaki, I. \& Wiklund, T., (2011) Assessment of reproductive biomarkers in three-spined stickleback (Gasterosteus aculeatus) from sewage effluent recipients. Environmental Toxicology, 28: 229-237. doi: 10.1002/tox.20715

Brion, F., Rogerieux, F., Noury, P., Migeon, B., Flammarion, P., Thybaud, E. \& Porcher, J.M. (2000). Two-step purification method of vitellogenin from three teleost fish species: rainbow trout (Oncorhynchus mykiss), gudgeon (Gobio gobio) and chub (Leuciscus cephalus). Journal of Chromatography. B, Biomedical Sciences and Applications, 737(1-2): 312. doi:10.1016/S0378-4347(99)00406-5

Colborn, T., vom Saal, F.S. \& Soto, A. M. (1993). Developmental effects of endocrine-disrupting chemicals in wildlife and humans. Environmental Health Perspectives, 101(5): 378-384. doi:10.2307/3431890

Coldham, N.G., Mehul, D., Sivapathasundaram, S., McDonnell, D.P., Conor, C. \& Sauer, M.J. (1997). Evaluation of a recombinant yeast cell estrogen screening assay. Environmental Health Perspectives, 105: 734-742. doi: $10.2307 / 3433729$

Çek, Ş. \& Sarıhan, F. (2010). The Effects of Sex Steroids of Endocrine Disrupting Chemicals on Fishes (in Turkish with English abstract). Ege Journal of Fisheries and Aquatic Sciences, 27(1): 41-46.

Donohoe, R.M. \& Curtis, L.R. (1996). Estrogenic activity of chlordecone, o,p'DDT and $0, p^{\prime}-D D E$ in juvenile rainbow trout: induction of vitellogenesis and interaction with hepatic estrogen binding sites. Aquatic Toxicology, 36: 31 52. doi:10.1016/S0166-445X(96)00799-0

Fakıoğlu, Ö. \& Polatsü, S. (2005). Determination of external phosphorus loading in Mogan Lake (Ankara) following some restoration measures (in Turkish with English abstract) Yuzuncu Yil University Journal of Agricultural Sciences, 15(1): 63-69.

Fenech, M., (2000). The in vitro micronucleus technique. Mutation Research 455, 81-95. doi:10.1016/S0027-5107(00)00065-8

Fenech, M., Holland, N., Chang, W.P., Zeiger, E. \& Bonassi, S. (1999). The human micronucleus project-an international collaborative study on the use of micronucleus technique for measuring DNA damage in humans. Mutation Research, 428: 271-283. PII:S1383-57429900053-8.

Hennies, M., Wiesmann, M., Allner, B. \& Sauerwein, H. (2003). Vitellogenin in carp (Cyprinus carpio) and perch (Perca fluviatilis): purification, characterization and development of an ELISA for the detection of estrogenic effects. The Science of the Total Environment, 309(1-3), 93103. doi:10.1016/S0048-9697(03)00005-6
Balıkçılık faaliyetleri açısından su sitemlerinin prodüktiviteleri üzerinde etkili olabilecek besin kaynakları ve ortam canlıları arasındaki ilişkilerde etkilenme durumları ve beklenen tehditler kısa ve uzun vadeli bilimsel takiplerle kontrol altında tutulmalıdır. Akuatik ortamlarda EDC'ler belirlenmeli, risk grubunda bulunan su kaynaklarında östrojenik etki mekanizmasına sahip bu kimyasalların bulunma düzeyleri acilen azaltılmalı ve bulaşma kaynaklarının önlenmesi için kalıcı çözümler üretilmelidir. Sucul ortamlarda akümülasyon özelliğine sahip EDC aktiviteli kimyasalların kullanımları yasaklanmalıdır. Endokrin bozucu olarak tespit edilen bütün kimyasalların seviyelerinin periyodik olarak takibi yapılmalıdır.

Jobling, S., Sheanan, D., Osborne, J.A., Matthiesen, P. \& Sumpter, J.P. (1996). Inhibition of testicular growth in rainbow trout (Oncorhynchus mykiss) exposed to alkylphenolic chemicals. Environmental Toxicology and Chemistry 15: 194-202. doi:10.1002/etc.5620150218

Jobling, S. \& Sumpter, J.P. (1993). Detergent components in sewage effluent are weakly estrogenic to fish: an in vitro study using rainbow trout (Oncorhynchus mykiss) hepatocytes. Aquatic Toxicology, 27: 361-372. doi:10.1016/0166-445X(93)90064-8

Karul, C., Soyupak, S., Çilesiz, A. F., Akbay, N. \& Germen, E. (2000). Case studies on the use of neural networks in eutrophication modeling. Ecological Modelling, 134: 145-152. doi:10.1016/S0304-3800(00)00360-4

Keleştemur, G.T. \& Özdemir, Y. (2010). Effect of low oxygen level on some blood parameter levels of fry rainbow trouts (Oncorhynchus mykiss, W. 1792). (in Turkish with English abstract). Journal of FisheriesSciences.com, 4(4): 310-317.

Lagler, K.F. (1956). Freshwater Fishery Biology. Dubuque, lowa: WMC. Brown Company. Publications.

Lazier, C.B. \& McKay, M.E. (1993). Vitellogenin gene expression in teleost fish In: Hochachka, P.W., Mommsen, T.P. (Eds.), Biochemistry and Molecular Biology of Fishes, Vol. 2. Elsevier, Amsterdam, The Netherlands.

Maltais, D. \& Roy, R.L. (2009). Purification and partial characterization of vitellogenin from shorthead redhorse (Moxostoma macrolepidotum) and copper redhorse (Moxostoma hubbsi) and detection in plasma and mucus with a heterologous antibody. Fish Physiology and Biochemistry, 35: 241250. doi:10.1007/s10695-008-9205-6

Meucci, V. \& Arukwe, A. (2005). Detection of vitellogenin and zona radiata protein expressions in surface mucus of immature juvenile Atlantic salmon (Salmo salar) exposed to waterborne nonylphenol. Aquatic Toxicology, 73(1): 1-10. PMID:15871908

Nagler, J.J., Ruby, S.M., Idler, D.R. \& So, Y.P. (1987). Serum phosphoprotein phosphorous and calcium levels as reproductive indicators of vitellogenin in highly vitellogenic mature female and estradiol-injected immature rainbow trout (Salmo gairdneri). Canadian Journal of Zoology, 65(10): 2421-2425. doi:10.1139/z87-365

Ndiaye, P., Forgue, J., Lamothe, V., Cauty, C., Tacon, P., Lafon, P., Davail, B., Fostier, A., Le Menn, F. \& Nunez, J. (2006). Tilapia (Oreochromis niloticus) vitellogenins: development of homologous and heterologous ELISAs and analysis of vitellogenin pathway through the ovarian follicle. Journal of Experimental Zoology Part A: Comparative Experimental Biology, 305A(7), 576-593. ISSN: 0022-104X.

Roubal, W.T., Lomax, D.P., Willis, M.L. \& Johnson, L.L. (1997). Purification and partial characterization of English sole (Pleuronectes vetulus) vitellogenin. Comparative Biochemistry and Physiology Part B: Biochemistry and Molecular Biology, 118(3): 613-622. doi:10.1016/S0305-0491(97)00241-1

Routledge, E.J., Sheahan, D., Desbrow, C., Brighty, G.C., Waldock, M. \& Sumpter, J.P. (1998). Identification of estrogenic chemicals in STW 
effluent 2: in vivo responses in trout and roach. Environmental Science and Technology, 32: 1559-1565. doi:10.1021/es970796a

Schiffmann, D. \& De Boni, U. (1991). Dislocation of chromatin elements in prophase induced diethylstilbestrol: a novel mechanism by which micronuclei can arise. Mutation Research, 246(1): 113-122. doi:10.1016/0027-5107(91)90113-3

Shore, L., Gurevitz, M. \& Shemesh, M. (1993). Estrogen as environmental pollutant. Bulletin of Environmental Contamination and Toxicology, 51 361-366. doi:10.1007/BF00201753

Stumpf, M., Ternes, T.A., llaber, K. \& Baumann, W. (1996). Determination of natural and synthetic estrogens in sewage plants and river water. Vom Wasser, 87: 251-261.

Sumpter, J.P. \& Jobling, S. (1995). Vitellogenesis as biomarker for estrogenic contamination of the aquatic environment. Environmental Health Perspective, 103(7): 173-178. doi:10.2307/3432529

Ternes, T.A., Stumph, M., Mueller, J., Haberer, K., Wilken, R.D. \& Servos, M. (1999). Behavior and occurrence of estrogens in municipal sewage treatment plants. I. Investigations in Germany, Canada and Brazil. Science of The Total Environment, 225: 81-90. doi:10.1016/S0048-9697(98)00334-9

Tyler, C.R. \& Sumpter, J. P. (1996). Oocyte growth and development in teleosts. Reviews in Fish Biology and Fisheries, 6: 287-318. doi:10.1007/BF00122584
Tyler, C.R. \& Sumpter, J. P. (1990). The development of a radioimmunoassay for carp (Cyprinus carpio) vitellogenin. Fish Physiology and Biochemistry, 8(2): 129-140. doi:10.1007/BF00004440

Tyler, C.R., van der Eerden, B., Jobling, S., Panter, G. \& Sumpter, J.P. (1996). Measurement of vitellogenin, a biomarker for exposure to oestrogenic chemicals, in a wide variety of cyprinid fish. Journal of Comparative Physiology B, 166: 418-426. doi:10.1007/BF02337886

Van den Belt, K., Verheyen, R. \& Witters, H. (2003). Comparison of vitellogenin responses in zebrafish and rainbow trout following exposure to environmental estrogens. Ecotoxicology and Environmental Safety, 56: 271-281. doi:10.1016/S0147-6513(03)00004-6

Van den Belt, K., Verheyen, R. \& Witters, H. (2001). Reproductive effects of ethynylestradiol and 4t-octylphenol on the zebrafish. Archives of Environmental Contamination and Toxicology, 41: 458-467. doi:10.1007/s002440010272

Yamanaka, Y., Mizuno,T., Sasai, Y., Kishi, M., Takeda, H., Kim C.H., Hibi, M. \& Hirano, T. (1998). A novel homeobox gene, dharma, can induce the organizer in a non-cell-autonomous manner. Genes and Development, 12(15), 2345-2353. doi:10.1101/gad.12.15.2345

Yamaguchi, A., Ishibashi, H., Kohra, S., Arizono, K., Kato, K., Nakahama, T., Kanno, Y., Inouye, Y. \& Tominaga, N. (2009). Expression analysis of estrogen-responsive genes vitellogenin 1 and 2 in liver of male medaka (Oryzias latipes) exposed to selective ligands of estrogen receptor subtypes. Journal of Health Science, 55(6): 930-938. doi:10.1248/jhs. 55.930 